\title{
ANALISIS STANDARISASI SARANA DAN PRASARANA TERHADAP PEMBINAAN PRESTASI ATLET BULUTANGKIS PB. CHAMPION KABUPATEN PEMALANG
}

\author{
Melani Indah Saputri ${ }^{1}$, Sugiarto ${ }^{2}$ \\ Universitas Negeri Semarang ${ }^{1,2}$ \\ e-mail: melaniindahsaputri@gmail.com
}

\begin{abstract}
ABSTRAK
Tujuan penelitian ini adalah untuk mengetahui kelengkapan serta standar sarana dan prasarana PB. Champion serta pembinaan prestasi PB. Champion. Jenis penelitian ini adalah kualitatif dengan metode observasi, wawancara dan dokumentasi. Narasumber penelitian terdiri dari Ketua, Pembina, atlet PB. Champion dan Pengelola GOR Melati. Pemeriksaan keabsahan data dengan triangulasi data. Teknik analisis data menggunakan reduksi data, penyajian data dan verifikasi atau kesimpulan. Berdasarkan hasil penelitian sarana dan prasarana pada PB. Champion sudah lengkap dengan lapangan, net atau jaring dan shuttlecock hanya saja kondisi lapangan tidak memadai dan tidak sesuai standar. Standar Prasarana Olahraga Berupa Bangunan Gedung Olahraga tidak lengkap karena tidak adanya fasilitas penunjang baik fasilitas untuk pemain, pengelola GOR maupun fasilitas umum. GOR yang digunakan tidak memenuhi kriteria kelayakan dari standar yang sudah ditetapkan. Dapat disimpulkan pembinaan prestasi belum dapat dilakukan secara maksimal karena kurangnya sarana dan prasarana penunjang serta beberapa sarana dan prasarana tidak memenuhi standar.
\end{abstract}

Kata Kunci: Analisis; Bulutangkis; Pembinaan Prestasi; Sarana Prasarana

\begin{abstract}
The purpose of this study was to determine the completeness and standard of PB. Champion facilities and infrastructure and achievement development. Champions. This type of research is qualitative with the method of observation, interviews and documentation. Research resource persons consist of the Chairperson, coaches, PB. Champion athletes and Manager of GOR Melati. Check the validity of the data by triangulation of data. The data analysis technique uses data reduction, data presentation and verification or conclusion. Based on the results of research on facilities and infrastructure at $P B$. Champion is complete with a field, net or net and shuttlecock, only the field conditions are inadequate and not up to standard. Sports Infrastructure Standards in the form of Sports Buildings are incomplete because there are no supporting facilities for players, GOR managers and public facilities. The GOR used does not meet the eligibility criteria of the established standards. It can be concluded that achievement development cannot be carried out optimally due to the lack of supporting facilities and infrastructure and some facilities and infrastructure do not meet the standards.
\end{abstract}

Keywords: Analysis; Badminton; Achievement Development; Facilities and Infrastucture

Dipublikasikan Oleh :

UPT Publikasi dan Pengelolaan Jurnal

Universitas Islam Kalimantan Muhammad Arsyad Al-Banjari Banjarmasin 


\section{PENDAHULUAN}

Olahraga adalah segala kegiatan yang sistematis untuk mendorong, membina, serta mengembangkan potensi jasmani, rohani, dan sosial (UU No 3 Tahun 2005, 2005). Kegiatan olahraga dapat dibedakan menjadi dua aktifitas. Dilihat dari sasarannya, kegiatan olahraga terdiri dari olahraga prestasi dan non prestasi. Olahraga prestasi dilakukan untuk mencapai kejuaraan tertentu dan tampak lebih menonjol di berbagai tingkat di Indonesia bahkan Internasional. Olahraga non prestasi dilakukan hanya untuk kebugaran jasmani seseorang dan terlihat lebih sepi dari publikasi dari pada olahraga prestasi. Keberadaan olahraga sekarang ini sudah menjadi bagian dari kegiatan masyarakat salah satunya adalah bulutangkis.

Bulutangkis adalah olahraga dan permainan yang sudah mendarah daging untuk masyarakat Indonesia. Bagi bangsa Indonesia olahraga bulutangkis merupakan olahraga semua lapisan masyarakat, karena dapat dimainkan oleh kalangan anak-anak hingga dewasa, baik laki-laki maupun perempuan untuk tujuan rekreasi dan hiburan, menjaga kualitas kesehatan dan kebugaran maupun untuk meraih prestasi (Putra dan Sugiyanto, 2016:176 dalam Pratama et al., 2020). Bulutangkis dinaungi oleh BWF (Badminton World Federation) sebagai induk organisasi internasional, dan PBSI (Persatuan Bulutangkis Seluruh Indonesia) sebagai induk organisasi nasional.

Perkembangan bulutangkis di Indonesia mengalami banyak pasang surut prestasi namun, prestasi bulutangkis Indonesia sangat menonjol di peta olahraga dunia. Prestasi yang dicapai tentu disertai dengan pembinaan yang terarah kepada para atlet. Prestasi olahraga yang optimal dapat dicapai dengan pembinaan yang baik dan benar disertai dengan latihan fisik, teknik, dan mental yang teratur, sistematis, terprogram dan berkesinambungan dengan pendekatan ilmu pengetahuan dan teknologi yang diterapkan dalam program latihan, sehingga dapat meningkatkan kualitas kemampuannya.

Melalui klub bulutangkis pembinaan dan pengembangan prestasi olahraga dapat dilakukan untuk memasyarakatkan olahraga dan mengolahragakan masyarakat serta mendorong masyarakat untuk berpartisipasi secara bertanggung jawab. Dalam olahraga bulutangkis, untuk meraih prestasi pelatih harus menerapkan pendekatan kepada atlet sesuai dengan prinsip-prinsip dasar latihan, yaitu tidak menerapkan begitu saja program latihan atletatlet senior kepada atlet-atlet junior dan mengabaikan kemampuan serta karakteristik pada atlet yang dimiliki pada pengalaman sebelumnya. Menurut Putra (2016) pembinaan merupakan faktor yang sangat berperan dalam dunia olahraga khususnya bulutangkis, pembinaan olahraga bulutangkis didukung oleh peran pembinaan yang sesuai dan tepat untuk meraih prestasi puncak.

Lancarnya pembinaan prestasi dapat diukur salah satunya dari ketersediaan sarana dan prasarana. Menurut Arham (2019) sarana merupakan perlengkapan yang dapat dipakai dan dipindah-pindahkan untuk mendukung fungsi kegiatan yang meliputi peralatan, perabotan, media pendidikan dan buku sedangkan prasarana adalah segala sesuatu yang merupakan penunjang utama terselenggaranya suatu proses. Secara umum, sarana dan prasarana merupakan komponen yang saling berkaitan dalam upaya suatu proses yang dilakukan sebagai penunjang terselenggaranya suatu kegiatan olahraga prestasi, salah satunya pada cabang olahraga bulutangkis. Apabila kedua hal ini tidak tersedia maka akan mempengaruhi hasil yang diharapkan tidak sesuai dengan rencana atau target.

Penelitian sebelumnya oleh Adib An'Amta Ahmad (2014) dilakukan untuk mengetahui hubungan motivasi belajar olahraga dan sarana prasarana keolahragaan terhadap prestasi belajar siswa cabang olahraga voli pantai di UPT SMA Negeri Olahraga Provinsi Jawa Timur. Hasil penelitian menghasilkan: (1) Semakin tinggi motivasi belajar, semakin tinggi prestasi

Dipublikasikan Oleh :

UPT Publikasi dan Pengelolaan Jurnal

Universitas Islam Kalimantan Muhammad Arsyad Al-Banjari Banjarmasin 
yang diperolehnya, (2) Semakin baik sarana prasarana yang disediakan sekolah, semakin tinggi prestasi yang diperolehnya. Penelitian oleh Arham (2019) dilakukan untuk mengetahui apakah ketersediaan sarana dan prasarana sudah memenuhi standar dalam pelaksanaan pembelajaran penjas. Hasil penelitian tersebut menunjukkan dari 6 Prasarana, sudah tersedia 4 prasarana atau $100 \%$ tergolong sangat baik, dan 2 prasarana atau $0 \%$ tergolong kurang sekali. Karena di SMA Negeri 3 Makassar tidak terdapat lapangan bulutangkis dan aula senam.

Kabupaten Pemalang merupakan salah satu daerah yang memiliki banyak pembinaan klub-klub bulutangkis dan berpotensi melahirkan bibit atlet berprestasi di tingkat kabupaten, provinsi bahkan nasional. Lahirnya bibit berprestasi tentunya ditunjang dengan adanya fasilitas gedung olahraga, sarana dan prasarana yang memadai serta program pembinaan yang terstruktur dan sistematis, salah satunya adalah PB.Champion. Pembinaan prestasi yang dilakukan PB.Champion sudah berjalan dengan baik karena sudah melaksanakan sistem pembinaan dengan mengacu pada sistem pembinaan yang sudah terorganisir dengan program latihan. Akan tetapi sarana dan prasarana yang dimiliki masih kurang sehingga belum menunjang seluruh kegiatan pembinaan prestasi atlet dengan maksimal.

Penelitian ini bertujuan untuk mengetahui kondisi, kelengkapan dan standar sarana dan prasarana serta pembinaan prestasi yang dilakukan dengan sarana prasarana pada PB.Champion.

\section{METODE}

Jenis penelitian yang digunakan peneliti dalam penelitian ini adalah penelitian kualitatif. Penelitian ini bersifat deskriptif. Anggito dan Setiawan (2018: 9) dalam buku metodologi penelitian kualitatif mengungkapkan bahwa penelitian kualitatif menekankan pada pemahaman mengenai masalah-masalah dalam kehidupan sosial berdasarkan kondisi realistis atau natural setting yang holistis, kompleks, dan rinci. Selai itu, menurut Sugiyono (2011: 9) dalam buku metode penelitian kuantitatif kualitatif dan R \& D menyebutkan bahwa metode penelitian kualitatif adalah metode penelitian berlandaskan pada filsafat postpositivisme, digunakan untuk meneliti pada kondisi obyek yang alamiah, dimana peneliti adalah sebagai instrument kunci. Pendapat peneliti tentang penelitian deskriptif kualitatif akan dapat lebih menjelaskan dengan bahasa-bahasa yang dapat menggambarkan fenomena sehingga lebih sistematis. Fenomena tersebut baik berupa bentuk aktifitas karakteristik, perubahan, hubungan, dan perbedaan antara fenomena yang satu dengan fenomena yang lainnya. Jenis penelitian kualitatif lebih kepada penelitian mendalam dan akurat serta hasil dari penelitian akan lebih banyak berupa uraian deskriptif serta analisis sehingga pertanyaan dalam penelitian dapat terjawab.

Penelitian dilaksanakan pada tanggal 6 April sampai dengan 31 Mei 2021 di PB. Champion yang bertempat di Jl. Tunggul Kel. Sikayu Kecamatan Comal Kabupaten Pemalang. Sasaran dalam penelitian ini yaitu ketua PB. Champion, pelatih, atlet ( 2 atlet putra dan 2 atlet putri) dan pengelola GOR Melati.

Pengambilan sampel dilakukan secara purposive sampling, artinya dalam pengambilan sampel dilakukan dengan pertimbangan tertentu yaitu terhadap orang yang dianggap paling tahu dan paham dalam bidangnya sehingga mempermudah dalam pengambilan data yang diharapkan.

Teknik pengumpulan dilakukan dengan triangulasi (gabungan), analisis data bersifat induktif/kualitatif dan hasil penelitian kualitatif menekankan makna daripada generalisasi. Teknik pengumpulan data yang dilakukan dalam penelitian ini adalah melalui observasi, wawancara, dan dokumentasi.

Dipublikasikan Oleh :

UPT Publikasi dan Pengelolaan Jurnal

Universitas Islam Kalimantan Muhammad Arsyad Al-Banjari Banjarmasin 
Dalam penelitian kualitatif, yang menjadi instrumen atau alat penelitian adalah peneliti itu sendiri. Peneliti kualitatif sebagai human instrument, berfungsi menetapkan fokus penelitian, memilih informan sebagai sumber data, melakukan pengumpulan data, menilai kualitas data, analisis data, menafsirkan data dan membuat kesimpulan atas temuannya (Sugiyono, 2011: 222). Instrumen dalam penelitian ini yaitu melakukan observasi secara langsung kemudian wawancara dengan ketua, Pembina atau pelatih, staf pengelola GOR Melati dan atlet PB. Champion serta dilanjutkan dokumentasi sebagai pelengkap data penelitian.

Teknik analisis data dalam penelitian ini dilakukan dengan tiga komponen yaitu data reduction (reduksi data) yaitu merangkum, memilih hal-hal pokok, memfokuskan pada halhal penting. Selanjutnya yaitu data display (penyajian data) yaitu menyajikan data dalam bentuk uraian singkat, bagan, hubungan antar kategori dan sejenisnya, terakhir yaitu conclusion drawing/verification (kesimpulan) yaitu temuan baru berupa deskripsi atau gambaran suatu obyek yang sebelumnya belum terlihat jelas sehingga setelah diteliti menjadi jelas.

\section{HASIL DAN PEMBAHASAN}

Penelitian ini secara khusus memuat tentang kondisi sarana dan prasarana terhadap pembinaan prestasi atlet bulutangkis PB. Champion Kabupaten Pemalang. Penelitian berasal dari hasil observasi, wawancara dan dokumentasi terhadap sumber data. Berdasarkan analisis data yang diperoleh dari lapangan, berikut uraian informasi data serta kondisi sarana dan prasarana terhadap pembinaan prestasi atlet bulutangkis PB. Champion Kabupaten Pemalang.

Tabel 1. Data Sarana dan Prasarana Bulutangkis PB. Champion

\begin{tabular}{lll}
\hline No & Sarana dan Prasarana & Banyaknya \\
\hline 1. & Lapangan & 4 \\
2. & Net & 4 \\
3. & Shuttlecock & 30 slop \\
4. & Toilet & 2 \\
5. & Kantin & 1 \\
6. & Tempat parkir & 1 \\
\hline
\end{tabular}

Keterangan: Data primer yang diolah, 2021

Peraturan Menteri Pemuda dan Olahraga Nomor 0445 Tahun 2014 (2014: 6) menetapkan ketentuan tentang klasifikasi penggunaan gedung olahraga, dalam hal ini GOR Melati termasuk dalam gedung olahraga tipe B dengan jumlah lapangan bulutangkis sebanyak 4 dapat digunakan untuk pertandingan nasional, pertaningan lokal dan latihan. Namun, dengan kondisi prasarana yang terbatas membuat GOR Melati tidak layak digunakan untuk pelaksanaan pertandingan nasional maupun lokal. Fasilitas-fasilitas yang ada sangat terbatas, tidak ada fasilitas umum seperti tribun penonton, fasilitas ibadah, dan toilet umum.

Dipublikasikan Oleh :

UPT Publikasi dan Pengelolaan Jurnal

Universitas Islam Kalimantan Muhammad Arsyad Al-Banjari Banjarmasin 
Tabel 2. Data Standar Sarana dan Prasarana Bulutangkis PB. Champion

\begin{tabular}{|c|c|c|c|c|c|c|}
\hline \multirow[b]{2}{*}{ No. } & \multirow[b]{2}{*}{$\begin{array}{l}\text { Sarana dan } \\
\text { Prasarana }\end{array}$} & \multirow[b]{2}{*}{ Standarisasi } & \multicolumn{2}{|l|}{ Kondisi } & \multicolumn{2}{|c|}{ Keterangan } \\
\hline & & & Memadai & $\begin{array}{l}\text { Tidak } \\
\text { Memadai }\end{array}$ & $\begin{array}{l}\text { Sesuai } \\
\text { Standar }\end{array}$ & $\begin{array}{l}\text { Tidak } \\
\text { Sesuai } \\
\text { Standar }\end{array}$ \\
\hline 1. & $\begin{array}{l}\text { a. Lantai } \\
\text { b. Ukuran } \\
\text { lapangan } \\
\text { c. Daerah } \\
\text { bebas } \\
\text { penonton }\end{array}$ & $\begin{array}{l}\text { Keras, rata dan } \\
\text { rapat (tidak ada } \\
\text { celah), tidak } \\
\text { licin } \\
\text { Panjang = } 13.4 \\
\mathrm{~m} \\
\text { Lebar }=6.10 \mathrm{~m} \\
1.25 \mathrm{~m}\end{array}$ & $\begin{array}{l}\checkmark \\
\checkmark \\
\checkmark\end{array}$ & $\checkmark$ & $\begin{array}{l}\checkmark \\
\checkmark \\
\checkmark\end{array}$ & $\checkmark$ \\
\hline 2. & $\begin{array}{l}\text { Ketinggian } \\
\text { gedung }\end{array}$ & $8 \mathrm{~m}$ & $\checkmark$ & & $\checkmark$ & \\
\hline 3. & $\begin{array}{l}\text { Net } \\
\text { bulutangkis } \\
\text { a. Tinggi net }\end{array}$ & $\begin{array}{l}\text { Dari tengah = } \\
1.52 \mathrm{~m} \\
\text { Dari pinggir }= \\
1.55 \mathrm{~m}\end{array}$ & $\begin{array}{l}\checkmark \\
\checkmark\end{array}$ & & $\begin{array}{l}\checkmark \\
\checkmark\end{array}$ & \\
\hline 4. & Shuttlecock & $\begin{array}{l}\text { Laju kecepatan } \\
\text { sesuai }\end{array}$ & $\checkmark$ & & $\checkmark$ & \\
\hline
\end{tabular}

Keterangan: Data primer yang diolah, 2021

Sarana dan prasarana merupakan satu kesatuan yang harus ada dalam melakukan kegiatan apapun, salah satunya melakukan pembinaan prestasi bulutangkis. Penelitian sebelumnya menyebutkan bahwa sarana dan prasarana adalah faktor yang harus ada pada setiap upaya pembinaan olahraga untuk mendukung peningkatan prestasi atlet agar tercapainya tujuan utama pembinaan (Santoso et al., 2017).

Berdasarkan ketentuan yang ditetapkan oleh Badminton World Federation (BWF) sebagai induk organisasi bulutangkis Internasional, menetapkan adanya sarana dan prasarana agar permainan bulutangkis dapat dilakukan yaitu lapangan, net atau jaring dan shuttlecock. Berdasarkan pernyataan tersebut, sarana dan prasarana bulutangkis yang digunakan PB. Champion sudah lengkap untuk dapat melaksanakan pembinaan pada atlet. Berdasarkan Peraturan Menteri Pemuda dan Olahraga Nomor 0445 Tahun 2014 tentang Standar Prasarana Olahraga Berupa Bangunan Gedung Olahraga, GOR yang digunakan untuk kegiatan pembinaan tidak memenuhi standar. Peraturan Menteri Pemuda dan Olahraga Nomor 0445 Tahun 2014 (2014: 6) menetapkan ketentuan tentang klasifikasi penggunaan gedung olahraga,

Dipublikasikan Oleh :

UPT Publikasi dan Pengelolaan Jurnal

Universitas Islam Kalimantan Muhammad Arsyad Al-Banjari Banjarmasin 
dalam hal ini GOR Melati termasuk dalam gedung olahraga tipe B dengan jumlah lapangan bulutangkis sebanyak 4 dapat digunakan untuk pertandingan nasional, pertandingan lokal dan latihan. Namun, dengan kondisi prasarana yang terbatas membuat GOR Melati tidak layak digunakan untuk pelaksanaan pertandingan lokal maupun nasional. Fasilitas-fasilitas yang ada sangat terbatas, tidak ada fasilitas umum seperti tribun penonton, fasilitas ibadah, dan toilet umum.

Badminton World Federation (BWF) sebagai organisasi tertinggi bulutangkis menetapkan peraturan bulutangkis sesuai standar, permukaan lapangan dianjurkan terbuat dari kayu atau bahan sintetis lunak agar tidak mengakibatkan cidera pada atlet, sedangkan permukaan lapangan yang dibuat dari beton atau bahan sintetis yang keras sangat tidak dianjurkan karena dapat mengakibatkan atlet mengalami cidera. Lapangan bulutangkis harus keras dan rata serta tidak licin. Berdasarkan Peraturan Menteri Pemuda dan Olahraga Nomor 0445 Tahun 2014 (2014: 36) tentang lantai arena disebutkan bahwa untuk permukaan lantai harus rata dan rapat (tidak ada celah sambungan atau renggangan), permukaan lantai harus tidak licin, permukaan lantai harus mudah dibersihkan tidak mudah aus dan tidak boleh luntur. Berdasarkan ketentuan-ketentuan tersebut, lapangan yang digunakan PB. Champion tidak memenuhi standar. Pernyataan tersebut dibuktikan dengan kondisi lapangan yang tidak memadai, lapangan yang digunakan PB. Champion terbuat dari keramik yang memiliki celah antar keramik. Beberapa bagian lapangan tidak rata dan berlubang. Lapangan yang digunakan seringkali licin hal ini disebabkan karena tidak meratanya cat pada permukaan lapangan. jarak antar lapangan 1,25 m sudah memenuhi standar yang ditentukan oleh Badminton World Federation (BWF) yaitu 1,2 m. Daerah bebas penonton dari lapangan 1,5 m juga sudah memenuhi standar yang ditentukan Badminton World Federation (BWF) yaitu 1,25 m. Net yang digunakan PB. Champion sudah menggunakan net dengan standar nasional dan sesuai dengan standar yang ditetapkan Badminton World Federation (BWF) untuk ketinggian net. Shuttlecock yang digunakan selama latihan juga sudah memadai sesuai dengan standar. Penggunaan shuttlecock sebagai sarana selama latihan boleh berbeda dari standar yang telah ditentukan untuk pertandingan nasional maupun internasional asalkan laju kecepatan sesuai dengan pemain yang menggunakan.

Fasilitas penunjang dalam pembangunan gedung olahraga, GOR yang digunakan memiliki ukuran $35 \mathrm{~m}$ x $18 \mathrm{~m}$ tanpa adanya tribun bagi penonton. Ketinggian GOR 9,5 m dalam hal ini sudah memenuhi standar sesuai dengan ketetapan pada Peraturan Menteri Pemuda dan Olahraga Nomor 0445 Tahun 2014 tentang Standar Prasarana Olahraga Berupa Bangunan Gedung Olahraga. GOR di desain untuk kegiatan latihan bulutangkis dan umum serta untuk bermain futsal. Berdasarkan pernyataan tersebut, prasarana berupa gedung olahraga yang digunakan tidak memenuhi standar kriteria kelayakan GOR.

Prestasi olahraga dapat dicapai apabila disertai pembinaan yang direncanakan dan dilaksanakan dengan baik (Slamet et al., 2019). Menurut Slamet, 2019 selain membutuhkan sarana dan prasarana yang memadai juga dibutuhkan pembinaan prestasi pada usia dini. Pembinaan prestasi dilakukan secara terstruktur dan berkesinambungan. Program-program pada pembinaan dilakukan secara jelas dan terarah sesuai dengan konsep periodesasi dan tahapan-tahapan pembinaan yang sistematis mulai dari tahap pemassalan, pembibitan hingga pembinaan prestasi.

Berdasarkan hasil penelitian yang dilakukan di PB. Champion Kabupaten Pemalang, pembinaan yang dilakukan sudah baik dan sesuai dengan jenjang pembinaan olahraga, yaitu pembibitan dan pembinaan prestasi. Pada tahap pemassalan tidak diperlukan dikarenakan sudah terfokus pada satu cabang olahraga, yaitu bulutangkis. Pada tahap pembibitan, pelatih

Dipublikasikan Oleh :

UPT Publikasi dan Pengelolaan Jurnal

Universitas Islam Kalimantan Muhammad Arsyad Al-Banjari Banjarmasin 
dan pengurus lainnya melakukan pengawasan dan penyeleksian terhadap individu yang memiliki potensi pada cabang olahraga bulutangkis untuk selanjutnya dibina dan dilatih oleh pelatih dalam proses pengembangan bakat. Pada tahap pembinaan prestasi, bibit-bibit atlet ini diberikan program-program latihan yang terstruktur, terarah dan berkesinambungan. Selain itu, diterapkan juga tahap pembentukan dan pemantapan. Pada tahap pembentukan, diberikan tingkatan latihan lebih pada pukulan, fisik, taktik, teknik dan mental. Sedangkan pada tahap pemantapan, atlet diberikan keleluasaan untuk melakukan evaluasi terhadap penampilan masing-masing individu yang nantinya dapat diimplementasikan lebih baik lagi. PB. Champion melaksanakan latihan sebanyak 5 kali dalam satu minggu dengan rincian sebagai berikut.

Tabel 1. Jadwal Latihan PB. Champion

\begin{tabular}{cc}
\hline Hari & Waktu \\
\hline Senin & $14.00-18.00$ \\
\hline Selasa & $14.00-18.00$ \\
\hline Rabu & $14.00-18.00$ \\
\hline Jum'at & $14.00-18.00$ \\
\hline Minggu & $09.00-12.00$
\end{tabular}

Keterangan: Data primer yang diolah, 2021

Pembinaan prestasi dapat berjalan dengan adanya pelatih untuk mentransfer ilmu dan pengetahuan tentang dunia olahraga khususnya bulutangkis kepada atlet secara lengkap baik dari segi teknik, taktik dan mental. PB. Champion Kabupaten Pemalang memiliki pelatih sebanyak 3 terdiri dari 1 pelatih utama dan 2 asisten pelatih. Peran pelatih disini memberikan pembinaan kepada atlet, memberikan arahan, mengajarkan teknik dan taktik bermain bulutangkis serta memberikan target kejuaraan pada atlet. Selain itu, pelatih PB. Champion harus mampu mengerti karakter masing-masing atlet. Pelatih juga harus mampu berperan sebagai orang tua atlet sebagaimana perasaan ayah kepada anaknya. Hal ini dilakukan agar terjalin hubungan yang kondusif antara pelatih dan atlet serta mampu menilai semua hal secara objektif.

Program latihan di PB. Champion Kabupaten Pemalang dibuat oleh pelatih dan diberikan berdasarkan kemampuan masing-masing atlet. Terdapat perbedaan dalam programprogram latihan yang diberikan untuk usia dini, anak-anak, pemula dan atlet yang sudah bisa atau senior. Bentuk program latihan yang dilaksanakan PB. Champion terdiri dari latihan drilling, stroke, shadow raket, shadow dengan kok, latihan fisik, latihan tanding, home event. PB. Champion juga menerapkan program latihan uji coba dengan klub lain baik di dalam kota maupun luar kota. Setiap pertemuan, selalu diawali dengan pemanasan yaitu berlari memutari lapangan dengan durasi waktu 10-30 menit. Kemudian dilanjutkan dengan latihan fisik. Pada latihan fisik ini terdapat program yang berbeda yang diberikan untuk atlet pemula dan atlet senior. Setelah itu, dilanjutkan dengan latihan drilling, stroke guna meningkatkan kemampuan taktik dan teknik masing-masing atlet. Kemudian di akhir pertemuan, atlet diberikan latihan tanding dengan teman sesuai tingkatan umur dan kemampuan hingga berbeda umur dan beda kemampuan. Tujuan diberikan latihan tanding ini yaitu guna melatih mental atlet ketika menghadapi pertandingan sesungguhnya. Setelah semua latihan dilaksanakan, kemudian dilakukan evaluasi di akhir pertemuan. Evaluasi dilakukan guna mengetahui tingkat

Dipublikasikan Oleh :

UPT Publikasi dan Pengelolaan Jurnal

Universitas Islam Kalimantan Muhammad Arsyad Al-Banjari Banjarmasin 
penguasaan masing-masing atlet terhadap kemampuan yang dimiliki saat ini sehingga dalam pelaksanaan latihan selanjutnya dapat mengurangi kekurangan yang ada.

Pembinaan prestasi yang telah dilakukan PB. Champion menghasilkan capaian akhir yang cukup baik pada atlet. Pada kejuaraan-kejuaraan yang diselenggarakan di dalam kota sering kali PB. Champion memperoleh predikat sebagai juara umum. Dalam pekan olahraga yang diselenggarakan untuk tingkat sekolah baik SD, SMP dan SMA atlet PB. Champion juga banyak meraih prestasi dan seringkali lanjut hingga tingkat provinsi. Namun, untuk tingkat provinsi pelatih tidak memasang target juara pada atlet hanya sebatas untuk mencari pengalaman dan memotivasi untuk bermain dengan maksimal sesuai kemampuan yang dimiliki. Hal tersebut dilihat salah satunya dari faktor sarana dan prasarana yang dimiliki. Berikut catatan prestasi atlet PB. Champion 3 tahun terakhir :

Tabel 4. Daftar Prestasi Atlet PB. Champion 3 Tahun Terakhir

\begin{tabular}{|c|c|c|}
\hline Kejuaraan & Tingkat & Prestasi \\
\hline POPDA SD 2019 & Kabupaten & Juara 1 Putra \\
\hline POPDA SMP 2019 & Kabupaten & $\begin{array}{l}\text { Juara } 2 \text { Putri } \\
\text { Juara } 1 \text { Putra } \\
\text { Juara } 2 \text { Putra }\end{array}$ \\
\hline POPDA SMA 2019 & Kabupaten & $\begin{array}{c}\text { Juara } 1 \text { Putra } \\
\text { Juara } 2 \text { Putra } \\
\text { Juara } 1 \text { Putri } \\
\end{array}$ \\
\hline Kendal Open 2019 & Jawa Tengah & $\begin{array}{l}\text { Juara } 1 \text { Tunggal Pemula Putra } \\
\text { Juara } 3 \text { Tunggal Pemula Putra }\end{array}$ \\
\hline Bupati Cup VII 2018 & Kabupaten & $\begin{array}{c}\text { Juara } 1 \text { Tunggal Putri } \\
\text { Juara } 2 \text { Tunggal Putri } \\
\text { Juara } 1 \text { Tunggal Anak Putra Madya } \\
\text { Juara } 1 \text { Tunggal Anak Putra Utama } \\
\text { Juara } 2 \text { Tunggal Anak Putra Utama } \\
\text { Juara } 3 \text { Tunggal Anak Putra Utama } \\
\text { Juara } 1 \text { Tunggal Pemula Putri } \\
\text { Juara } 3 \text { Tunggal Pemula Putra } \\
\text { Juara } 1 \text { Tunggal Remaja Putra } \\
\text { Juara } 1 \text { Tunggal Remaja Putri } \\
\text { Juara } 2 \text { Tunggal Remaja Putri } \\
\text { Juara } 3 \text { Tunggal Remaja Putri }\end{array}$ \\
\hline Sinar Cristal Cup 2018 & Kabupaten & $\begin{array}{c}\text { Juara } 1 \text { Tunggal Pemula Putra } \\
\text { Juara } 2 \text { Tunggal Pemula Putra } \\
\text { Juara } 1 \text { Tunggal Pemula Putri } \\
\text { Juara } 2 \text { Tunggal Pemula Putri } \\
\text { Juara } 2 \text { Tunggal Anak Putri } \\
\text { Juara } 1 \text { Tunggal Remaja Putri }\end{array}$ \\
\hline $\begin{array}{l}\text { USM CUP XII Semarang } \\
2018\end{array}$ & Jawa Tengah & $\begin{array}{l}\text { Juara } 3 \text { Tunggal Anak Putra } \\
\text { Juara } 3 \text { Ganda Pemula Putra }\end{array}$ \\
\hline
\end{tabular}

Dipublikasikan Oleh :

UPT Publikasi dan Pengelolaan Jurnal

Universitas Islam Kalimantan Muhammad Arsyad Al-Banjari Banjarmasin 
Juara 3 Ganda pemula Putri

Keterangan: Data primer yang diolah, 2021

\section{PENUTUP}

Berdasarkan hasil penelitian dan sarana dan prasarana bulutangkis yang dimiliki PB. Champion Kabupaten Pemalang sudah lengkap dari adanya lapangan, net atau jarring shuttlecock. Namun untuk prasarana berupa bangunan gedung olahraga yang digunakan PB. Champion tidak lengkap, hal ini dibuktikan dengan tidak adanya fasilitas-fasilitas penunjang baik untuk pemain, pengelola GOR dan fasilitas umum. Sarana prasarana bulutangkis yang dimiliki PB. Champion untuk lapangan yang digunakan dalam kondisi tidak memadai dan tidak memenuhi standar, sedangkan sarana yang lain dalam kondisi memadai dan sesuai standar. Pembinaan prestasi yang dilakukan sudah baik sesuai dengan sistem pembinaan olahraga yang digunakan di Indonesia. Namun pembinaan prestasi belum dapat dilakukan dengan maksimal karena kurangnya sarana dan prasarana penunjang dalam pelaksanaan kegiatan pembinaan. Berdasarkan kesimpulan yang telah dijabarkan, peneliti mempunyai beberapa saran yaitu bagi pemilik atau pengelola GOR Melati lebih memperhatikan kelengkapan fasilitas yang dibutuhkan dalam pembangunan gedung olahraga. Untuk memaksimalkan pembinaan prestasi, perlu diperhatikan kembali sarana dan prasarana dalam suatu cabang olahraga maupun standar pembangunan gedung olahraga serta bagi pelatih, dapat membuat sarana tambahan seperti raket pemberat yang digunakan ketika melakukan drilling, shadow maupun stoke untuk melatih kekuatan lengan, maupun membuat beban dari botol untuk kekuatan pergelangan tangan.

\section{REFERENSI}

Adib An'Amta Ahmad, D. N. (2014). Hubungan Mootivasi Belajar olahraga Dan Sarana Prasarana Keolahragaan Terhadap Prestasi Belajar Siswa Cabang Olahraga Voli Pantai Di UPT SMA Negeri Olahraga Provinsi Jawa Timue. Jurnal Inspirasi Manajemen Pendidikan, 3(3), 66-71.

Anggito, A, \& S. Johan. (2018). Metodologi Penelitian Kualitatif. Sukabumi: CV Jejak.

Arham, S. (2019). Ketersediaan Sarana dan Prasarana Terhadap Pelaksanaan Pembelajaran Pendidikan Jasmani di SMA Negeri 3 Makassar. Celebes Education Review, 1, 53-58.

Peraturan Menteri Pemuda dan Olahraga Nomor 0445 Tahun 2014. (2014). PERATURAN MENTERI PEMUDA DAN OLAHRAGA REPUBLIK INDONESIA NOMOR 0445 TAHUN 2014 TENTANG STANDAR PRASARANA OLAHRAGA BERUPA BANGUNAN GEDUNG OLAHRAGA.

Pratama, A., Supriyadi, S., \& Raharjo, S. (2020). SURVEI MANAJEMEN PEMBINAAN PRESTASI CABANG OLAHRAGA BULUTANGKIS DI PB GANESHA KOTA BATU. Jurnal Sport Science.

Putra, R. A. (2016). Analisis Pembinaan Prestasi Cabang Olahraga Sepakbola Di Akademi Triple' S U-17 Kabupaten Kediri. Jurnal Kesehatan Olahraga, 06(2), 433-440.

Santoso, H. P., Rahayu, T., \& Rahayu, S. (2017). Journal of Physical Education and Sports

Dipublikasikan Oleh :

UPT Publikasi dan Pengelolaan Jurnal

Universitas Islam Kalimantan Muhammad Arsyad Al-Banjari Banjarmasin 
Pembinaan Bulutangkis di Kota Magelang ( Penelitian Evaluatif Klub-klub Bulutangkis di Kota Magelang ) Abstrak. Journal of Physical Education and Sports, 6(2), 133-140.

Slamet, H. R. K. A. R. (2019). Management Achievement Coached Badminton Club Klaten Districts 2019th. International Journal of Multicultural and Multireligious Understanding, 6(3), 33.

Sugiyono. 2011. METODE PENELITIAN KUANTITATIF KUALITATIF DAN R\&D. Bandung: Alfabeta.

UU No 3 Tahun 2005. (2005). Undang-Undang Republik Indonesia Nomor 3 Tahun 2005 Tentang Sistem Keolahragaan Nasional. Presiden RI, 1, 1-53. 